\title{
GENETIC BASIS OF HETEROSIS AND PREDICTION OF HYBRID PERFORMANCE
}

\author{
Reif, J.C. ${ }^{*}$, Hahn, V. ${ }^{1}$ and Melchinger, A.E. ${ }^{2}$ \\ ${ }^{1}$ State Plant Breeding Institute, University of Hohenheim, \\ Fruwirthstr. 21, 70593 Stuttgart, Germany \\ 2 Institute of Plant Breeding, Seed Science and Population Genetics, \\ University of Hohenheim, Fruwirthstr. 21, 70593 Stuttgart, Germany
}

Received: October 23, 2012

Accepted: December 01, 2012

\section{SUMMARY}

Overview and scope of the presentation: Efficient exploitation of heterosis is central for successful hybrid breeding in sunflower. Here we discussed important genetic hypotheses of the phenomenon of heterosis including dominance, overdominance, and epistasis. Moreover, we presented different approaches suggested for prediction of hybrid performance.

Outline of recent major discoveries: Several experimental designs have been proposed to study the causes of heterosis. Among them, QTL analyses based on triple test cross in combination with the immortalized $\mathrm{F}_{2}$ design or the use of triple test cross designs based on near-isogenic lines are of particular interest. Several approaches have been used to predict hybrid performance using phenotypic, genomic, transcriptomic, and metabolomic data. Prediction accuracies have been studied using experimental data of maize, which clearly points towards the large potential for knowledge-based hybrid breeding.

Perceived significant gaps in research, current debates, and perspectives for future directions of research: Experimental design and quantitative genetic theory is ready to be applied in sunflower to study the genetic basis of heterosis. Furthermore, we speculate that genomic selection possesses great potential to revolutionize hybrid prediction in sunflower.

Key words: heterosis, hybrid performance, sunflower, genomic selection

\section{INTRODUCTION}

The exploitation of heterosis through hybrid breeding is one of the landmark achievements in plant breeding (Duvick, 2001). The genetic basis of the phenomenon of heterosis has been studied intensively during the past century. Vast data sets were generated, analyzed, and the gathered information was discussed at three International conferences, at Iowa State College in Ames (Gowen, 1952), at CIMMYT

* Corresponding author: e-mail: jochreif@uni-hohenheim.de; e-mail: melchinger@uni-hohenheim.de 
in Mexico City (Coors and Pandey, 1999), and at the University of Hohenheim in Stuttgart (Melchinger, 2010). Genetic hypotheses are amongst the oldest but still most prevailing explanations for heterosis (Lamkey and Edwards, 1999). The dominance hypothesis explains heterosis by the cumulative effect of favorable alleles exhibiting either partial or complete dominance. The overdominance hypothesis assumes overdominant gene action at many loci and the epistasis hypothesis attributes heterosis to epistatic interactions between non-allelic genes. The relevance of the three hypotheses has been investigated intensively using phenotypic data (for review, see Reif et al., 2005) and also through molecular marker-aided QTL mapping.

Reliable prediction of single-cross performance is very important in hybrid breeding, because it is difficult to evaluate inbred lines in numerous cross combinations. Several prediction approaches have been suggested using phenotypic data with coancestry coefficients calculated from pedigree records or marker data (for review, see Schrag et al., 2009). Moreover, genomic selection based on dense molecular marker profiles has the potential to assist breeders in the selection of the most promising hybrids for field evaluation (Piepho, 2009).

Here we:

1) reviewed various hypotheses on the genetic causes of heterosis and various experimental designs used to support or refute them, and

2) summarized the various methods used to predict hybrid performance of inter-group single-crosses in maize.

\section{THE GENETIC BASIS OF HETEROSIS}

Thirteen years after the International congress in Mexico City on "The genetics and exploitation of heterosis in crops" (Coors and Pandey, 1999) and 60 years after the Heterosis conference held at Iowa State College (Gowen, 1952), the third conference on "Heterosis in Plants" was organized at the University of Hohenheim, where the progress on the biological processes underlying heterosis and experimental evidence supporting or refuting them were discussed (Melchinger, 2010). This article gives a brief overview of the genetic hypothesis of heterosis. Detailed information on experimental results on the genetic basis of heterosis in crops can be found in the Special Issue on "Heterosis in Plants" (Melchinger, 2010). Moreover, we do not discuss physiological and molecular hypotheses of heterosis, which are reviewed also in detail elsewhere (e.g., Hochholdinger and Hoecker, 2007).

\section{Quantitative genetic basis of heterosis}

For our purpose, we will define heterosis as the difference between the hybrid and the mean of its two parents (Schnell, 1961). Considering only digenic epistasis and using the $\mathrm{F}_{2}$ metric (Cockerham, 1954; Yang, 2004), Melchinger et al. (2007a) derived the following quantitative genetic formula for heterosis:

$$
H=\sum_{i \in Q}\left(d_{i}-\frac{1}{2}\left(\sum_{j \in Q_{j}} a a_{i j}\right)\right.
$$


with $Q_{j}$ denoting the loci set $Q$ underlying the agronomic trait of interest excluding element $i, d_{i}$ being the dominance effect of locus $i$ and $a a_{i j}$ referring to the additive $\times$ additive epistatic effect between locus $i$ and $j$.

Consequently, heterosis can be explained by:

1) dominance or,

2) overdominance or,

3) by epistatic interactions between non-allelic genes.

For review, see Lamkey and Edwards (1999).

Moreover, on the basis of their findings, Melchinger et al. (2007a) defined the augmented dominance effect as the dominance effect at each locus minus half the sum of addi-tive $\times$ additive epistasis with all other loci.

The relevance of dominance, overdominance, or epistasis for heterosis has been investigated intensively using generation means analyses (for review, see Hallauer and Miranda, 1981). The outcomes are, however, of limited use as the estimated parameters reflect net gene effects and, therefore, positive and negative gene effects can cancel each other (Melchinger et al., 2007a). Studies based on secondmoment statistics and North Carolina Experiment III (Design III) proposed by Comstock and Robinson (1952) suggests that heterosis is caused by the cumulative action of a large number of dominant genes (Hallauer and Miranda, 1981). The limitation of the Design III is, however, the assumption of absence of epistasis. This drawback was partially overcome with the triple test cross design proposed by Kearsey and Jinks (1968), an elegant extension of the Design III. Nevertheless, even with a triple test cross design inferences about the importance of epistasis are critical as non-significant epistatic variances can be attributable either to absence of epistatic effects or to the low power of the statistical tests with the sample sizes commonly employed in experimental studies.

Molecular marker aided genetic analyses provided a new and powerful tool to study the genetic basis of heterosis in more detail. Using Design III in combination with QTL analyses facilitates a one-dimensional scan to identify loci exhibiting significant augmented dominance effects. QTL studies based on Design III in maize revealed a high power to map loci contributing to heterosis (Schön et al., 2010). Delineating augmented dominance effect into its components was until now hampered by the use of Design III (Melchinger et al., 2007a). The switch to triple testcross designs in combination with QTL mapping allows a two dimensional scan for cumulative additive $\times$ additive epistasis, but the two-dimensional scan is afflicted with reduced power to identify relevant epistatic interactions (Melchinger et al., 2008). As a potential solution, QTL mapping based on the triple test cross design can be combined with a subsequent use of an immortalized $\mathrm{F}_{2}$ population (Hua et al., 2003) to investigate heterotic $\mathrm{QTL}$ in more detail. Immortalized $\mathrm{F}_{2}$ populations possess great value to estimate dominance effect separately from the cumulative additive $\times$ additive effects (Melchinger et al., 2007a). Alternatively, triple test cross designs in combination with near-isogenic lines are an interesting approach to esti- 
HELIA, 35, Nr. 57, p.p. 1-8, (2012)

mate dominance effect separately from the cumulative additive $\times$ additive effects (Melchinger et al., 2007a; Reif et al., 2009). Summarizing, we are still at the beginning of understanding the complex mechanism of heterosis. In the future, appropriated experimental designs combined with advances in genomics will facilitate a more profound understanding of heterosis.

\section{PREDICTION OF HYBRID PERFRORMANCE}

\section{Hybrid prediction based on line per se performance or general combining ability effects}

For less complex traits, mid-parent performance serves as a good predictor for hybrid performance. In contrast, for complex traits, predicting the performance of single crosses based on the line per se performance is expected to be severely hampered by masking non-additive effects (Smith, 1986). This was also confirmed in sunflower with several experimental studies (e.g., Ortis et al., 2005).

For hybrid breeding, the relative magnitude of the variance due to general $\left(\sigma^{2} \mathrm{GCA}\right)$ and specific combining ability $\left(\sigma^{2} \mathrm{SCA}\right)$ is of particular interest (Melchinger et al., 1987). With predominance of $\sigma^{2} \mathrm{GCA}$ over $\sigma^{2} \mathrm{SCA}$, superior hybrids can be identified and selected mainly based on their prediction from general combining ability effects. Several experimental results in sunflower revealed a low $\sigma^{2}{ }_{\mathrm{GCA}} / \sigma^{2} \mathrm{SCA}$ ratio for grain yield (e.g., Gangappa et al., 1997; Škorić et al., 2000; Laureti and Del Gatto, 2001; Ortis et al., 2005; Abelardo de la Vega and Chapman, 2006). The $\sigma^{2} \mathrm{GCA} / \sigma^{2} \mathrm{SCA}$ ratio varies depending on the allele frequencies between parental populations (Reif et al., 2007). Increasing genetic divergence of the two parental populations tends to lead to a high ratio of $\sigma^{2}{ }_{\mathrm{GCA}}$ versus $\sigma^{2} \mathrm{SCA}$ (Fischer et al., 2008). Consequently the low $\sigma^{2} \mathrm{GCA} / \sigma^{2} \mathrm{SCA}$ ratio observed in sunflower may be due to the lack of genetically diverse heterotic groups (Cheres et al., 2000; Smith et al., 2009). Applying inter-population improvement programs in sunflower with a clear heterotic group concept possesses great potential to promote on a long term divergence among heterotic pools and therefore also to lead to a more favorable $\sigma^{2}{ }_{\mathrm{GCA}} / \sigma^{2} \mathrm{SCA}$ ratio.

\section{Predicting heterosis based on genetic distances}

Quantitative genetic theory suggests a linear relationship between heterosis of a hybrid and the genetic distance between its parents considering all loci underlying the quantitative trait of interest (Falconer and Mackay, 1996). Consequently, predicting hybrid performance based on mid-parent performance and genetic distances was suggested (for review, see Melchinger, 1999). Nevertheless, predicting heterosis in sunflower with estimates of genetic distances between the parental lines based on random DNA markers was not successful (Cheres et al., 2000). This low predicting ability can be explained by:

1) a poor association between heterozygosity estimated from marker data and heterozygosity at quantitative trait loci affecting the trait examined, 
2) a poor association between heterozygosity and heterosis at quantitative trait loci in the crosses examined (Charcosset et al., 1991), and

3) epistasis (Moll et al., 1965).

In a recent study in maize, Frisch et al. (2010) showed that prediction of hybrid performance with transcriptome-based distances was more precise than earlier prediction models using DNA markers. Nevertheless, the data was based on a limited set of 98 hybrids, and, therefore, this finding has to be substantiated with further studies.

\section{Phenotypic BLUP method}

Hybrid prediction based on best linear unbiased prediction (BLUP) showed large potential to predict hybrid performance in maize (for review, see Bernardo, 2002). The BLUP approach exploits information on genetic relationships among the parental inbreds based on coancestry coefficients estimated from either pedigree records or molecular markers. However, as the marker-based coancestry coefficients indicate overall expectations for the whole genome, the full potential of molecular markers is not exploited because specific genomic regions that are relevant for trait expression are ignored (Charcosset et al., 1991).

\section{Genomic selection for general combining ability}

Genomic selection was suggested in the context of animal breeding with great potential to revolutionize the design and implementation of livestock and crop breeding programs. Genomic selection differs from marker-assisted selection in that it abandons the objective to map the effect of individual genes and instead focuses on an efficient estimation of breeding values on the basis of a large number of molecular markers. As a first step in genomic selection, marker effects are estimated on the basis of a training set of genotypes, which are phenotyped and fingerprinted with dense marker data. In the second step, individuals related to the training population that have been genotyped but not phenotyped are selected based on marker effects. The precision of genomic selection to predict general combining ability effects have been evaluated using cross-validation and experimental data in maize (Albrecht et al., 2011; Zhao et al., 2012a, b, c). The accuracy was high, underlining the great potential of genomic selection for predicting general combining ability effects.

\section{Genomic selection for general and specific combining ability}

Genomic selection was also suggested to predict hybrid performance considering general as well as specific combining ability effects (e.g., Yu and Bernardo, 2007). First experimental results in maize underline the potential of this approach (van Eeuwijk et al., 2010). Nevertheless, the increase in the accuracy by considering besides the general also the specific combining ability greatly depends on the $\sigma^{2} \mathrm{GCA} / \sigma^{2} \mathrm{SCA}$ ratio. For maize with a predominance of $\sigma^{2} \mathrm{GCA}$ over $\sigma^{2} \mathrm{SCA}$ (Fischer et 
al., 2008), benefits obtained from estimating specific combining ability are limited. In contrast, for sunflower with a high relevance of $\sigma^{2} \mathrm{SCA}$, genomic selection approaches exploiting general and specific combining ability are of utmost interest.

\section{REFERENCES}

de la Vega, A. and Chapman, S.C., 2006. Multivariate analyses to display interactions between environment and general or specific combining ability in hybrid crops. Crop Sci. 46: 957967.

Albrecht, T., Wimmer, V., Auinger, H-J., Erbe, M., Knaak, C., Ouzunova, M., Simianer, H. and Schön, C.C., 2011. Genome-based prediction of test cross values in maize. Theor. Appl. Genet. 123: 339-350.

Bernardo, R., 2002. Quantitative traits in Plants. Stemma Press, Woodbury, Minnesota, USA.

Bernardo, R., and Yu, J., 2007. Prospects for genome-wide selection for quantitative traits in maize. Crop Sci. 47: 1082-1090.

Charcosset, A., Lefort-Buson, M. and Gallais, A., 1991. Relationship between heterosis and heterozygosity at marker loci: A theoretical computation. Theor. Appl. Genet. 81: 571575.

Cheres, M.T., Miller, J.F., Crane, J.M. and Knapp, S.L., 2000. Genetic distance as a predictor of heterosis and hybrid performance within and between heterotic groups in sunflower. Theor. Appl. Genet. 100: 889-894.

Cockerham, C.C., 1954. An extension of the concept of partitioning hereditary variance for analysis of covariance's among relatives when epistasis is present. Genetics 39: 859-882.

Comstock, R.E., and Robinson, H.F., 1952. Estimation of average dominance of genes. In: J.W. Gowen (Ed.), Heterosis. Iowa State College Press, Ames, IA. Pp. 494-516.

Coors, J.G., and Pandey, S., 1999. The genetics and exploitation of heterosis in crops. ASA, CSSA, SSSA, Madison, WI.

Duvick, D.N., 2001. Biotechnology in the 1930s: the development of hybrid maize. Nat. Rev. Genet. 2: 69-74.

Falconer, D.S., and Mackay, T.F., 1996. Introduction to Quantitative Genetics. $4^{\text {th }}$ ed. Longman Group Ltd., London.

Fischer, S., Möhring, J., Schön, C.C., Piepho, H-P., Klein, D., Schipprack, W., Utz, H.F., Melchinger, A.E. and Reif, J.C., 2008. Trends in genetic variance components during 30 years of hybrid maize breeding at the University of Hohenheim. Plant Breed. 127: 446451.

Frisch, M., Thiemann, A., Fu, J., Schrag, T.A., Scholten, S. and Melchinger, A.E., 2010. Transcriptome-based distance measures for grouping of germplasm and prediction of hybrid performance in maize. Theor. Appl. Genet. 120: 441-450.

Gangappa, E., Channakrishnaiah, K.M., Harini, M.S. and Ramesh, S., 1997. Studies on combining ability in sunflower (Helianthus annuus L.). Helia 20: 73-84.

Gowen, J.W., 1952. Heterosis. Iowa State College Press, Ames, IA.

Hallauer, A.R., and Miranda, J.B., 1981. Quantitative genetics in maize breeding. Iowa State University Press, Ames, USA.

Hochholdinger, F., and Hoecker, N., 2007. Towards the molecular basis of heterosis. Trends in Plant Sci. 12: 427-432.

Hua, J.P., Xing, Y.Z., Wu, W.R., Xu, C.G., Sun, X.L., Yu, S.B. and Zhang. Q.F., 2003. Single-locus heterotic effects and dominance-by-dominance interactions can adequately explain the genetic basis of heterosis in an elite rice hybrid. PNAS USA 100: 2574-2579.

Kearsey, M.J. and Jinks, J.L. 1968. A general method of detecting additive, dominance and epistatic variation for metrical traits. I. Theory. Heredity 23: 403-409.

Lamkey, K.R., and Edwards, J.W., 1999. Quantitative genetics of heterosis. In: J.G. Coors and S. Pandey (Ed.), The Genetics and Exploitation of Heterosis in Crops. ASA, CSSA, SSSA, Madison, WI. Pp. 31-48.

Lauretti, D., and Del Gatto, A., 2001. General and specific combining ability in sunflower (Helianthus annuus L.). Helia 24: 1-16.

Melchinger, A.E., 1999. Genetic diversity and heterosis. In: J.G. Coors, S. Pandey (Ed.), The Genetics and Exploitation of Heterosis in Crops. ASA, CSSA, and SSSA, Madison, WI. Pp. 99-18. 
Melchinger, A.E., 2010. The International Conference on "Heterosis in Plants". Theor. Appl. Genet. 120: 201-203.

Melchinger, A.E., Geiger, H.H., Seitz, G. and Schmidt, G.A., 1987. Optimum prediction of threeway crosses from single crosses in forage maize (Zea mays L.). Theor. Appl. Genet. 74: 339-345.

Melchinger, A.E., Utz, H.F., Piepho, H.P., Zeng, Z.B. and Schön, C.C., 2007a. The role of epistasis in the manifestation of heterosis-a systems-oriented approach. Genetics 177: 1815-1825.

Melchinger, A.E., Piepho, H.P., Utz, H.F., Muminović, J., Wegenast, T., Törjék, O., Altmann, T., Kusterer, B., Zeng, Z.B. and Schön, C.C., 2007b. Genetic basis of heterosis for growthrelated traits in Arabidopsis investigated by test cross progenies of near-isogenic lines reveals a significant role of epistasis. Genetics 177: 1827-1837.

Melchinger, A.E., Utz, H.F. and Schon, C.C., 2008. Genetic expectations of quantitative trait loci main and interaction effects obtained with the triple test cross design and their relevance for the analysis of heterosis. Genetics 178: 2265-2274.

Moll, R.H., Longquist, J.H., Fortuna, J.V. and Johnson, E.C., 1965. The relation of heterosis and genetic divergence in maize. Genetics 52: 139-144.

Ortis, L., Nestares, G., Frutos, E. and Machado, N., 2005. Combining ability analysis for agronomic traits in sunflower (Helianthus annuus L.). Helia 28: 125-134.

Piepho, H.P., 2009. Ridge regression and extensions for genome wide selection in maize. Crop Sci. 49: 1165-1176.

Reif, J.C., Hallauer, A.R. and Melchinger, A.E., 2005. Heterosis and heterotic pattern in maize. Maydica 50: 215-223.

Reif, J.C., Gumpert, F., Fischer, S. and Melchinger, A.E., 2007. Impact of genetic divergence on additive and dominance variance in hybrid populations. Genetics 176: 1931-1934.

Reif, J.C., Kusterer, B., Piepho, H.-P., Meyer, R.C., Altmann, T., Schön, C.C. and Melchinger, A.E., 2009. Unraveling epistasis with triple test cross progenies of near-isogenic lines. Genetics 181: 247-257.

Schnell, F.W., 1961. Heterosis and inbreeding effect. Schriftenreihe des Max-Planck-Instituts für Tierzucht und Tierernährung. Pp. 251-272.

Schön, C.C., Dhillon, B.S., Utz, H.F. and Melchinger, A.E., 2010. High congruency of QTL positions for heterosis of grain yield in three crosses of maize. Theor. Appl. Genet. 120: 321-332.

Schrag, T.A., Frisch, M., Dhillon, B.S. and Melchinger, A.E., 2009. Marker-based prediction of hybrid performance in maize single-crosses involving doubled haploids. Maydica 54: 353362.

Škorić, D., Jocić, S. and Molnar, I., 2000. General and specific combining abilities in sunflower. Proc. $15^{\text {th }}$ Int. Sunfl. Conf., Toulouse, France.

Smith, J., Stephen, C., Hoeft, E., Cole, G., Lu, H., Jones, E.S., Wall, S.J. and Berry, D.A., 2009. Genetic diversity among US sunflower inbreds and hybrids: Assessing probability of ancestry and potential for use in plant variety protection. Crop Sci. 49: 1295-1303.

Smith, O.S., 1986. Covariance between line per se and testcross performance. Crop Sci. 26: 540-543.

van Eeuwijk, F., Boer, M., Totir, L., Bink, M., Wright, D., Winkler, C., Podlich, D., Boldman, K., Baumgarten, A., Smalley, M., Arbelbide, M., ter Braak, C. and Cooper, M., 2010. Mixed model approaches for the identification of QTLs within a maize hybrid breeding program. Theor. Appl. Genet. 120: 429-440.

Yang, R.C., 2004. Epistasis of quantitative trait loci under different gene action models. Genetics 167: 1493-1505.

Zhao, Y., Gowda, M., Liu, W., Würschum, T., Maurer, H.P., Longin, C.F.H., Ranc, N. and Reif, J.C., 2012a. Accuracy of genomic selection in European maize elite breeding populations. Theor. Appl. Genet. 124: 769-776.

Zhao, Y., Gowda, M., Longin, C.F.H., Würschum, T., Ranc, N. and Reif, J.C., 2012b. Impact of selective genotyping in the training population on accuracy and bias of genomic selection. Theoretical and Applied Genetics 125: 707-713.

Zhao, Y., Gowda, M., Liu, W., Würschum, T., Maurer, H.P., Longin, C.F.H., Ranc, N., Piepho, H.P. and Reif, J.C., 2012c. Choice of shrinkage parameter and prediction of genomic breeding values in elite maize breeding populations. Plant Breeding. In press. 
